\title{
PERAN EKOSISTEM MANGROVE SEBAGAI HABITAT POPULASI \\ TUNTONG LAUT (Batagur borneoensis, Schlegel \& Muller, 1844)
}

\author{
Syifa Saputra \\ Pendidikan Biologi Fakultas Keguruan dan Ilmu Pendidikan \\ Universitas Almuslim \\ Syifa.mpbiounsyiah@gmail.com
}

\begin{abstract}
RINGKASAN
Terdegradasinya ekosistem mangrove dapat menyebabkan hilangnya biodiversitas mangrove dan keseimbangan layanan ekosistem mangrove. Terganggunya fungsi layanan ekosistem berdampak pada peran mangrove dan mengakibatkan hilangnya suatu spesies. Pengaruh faktor biotik dan abiotik dapat terjadi perubahan yang dapat memberikan kontribusi berbeda terhadap peranan ekosistem mangrove sebagai habitat alaminya. Interaksi antar jenis spesies akan berdampak pada menurunnya jumlah populasi suatu spesies terutama tuntong laut, jika habitatnya terganggu. Tuntong laut mempunyai tingkat sensitifitas yang tinggi terhadap lingkungan yang tercemar, serangan predator maupun aktivitas manusia. Jasa layanan ekosistem mangrove mampu meningkatkan peran dan fungsinya terhadap masuknya zat pencemar dari bahan organik. Selain dijadikan sebagai tempat mencari makan dan tempat berlindung dari serangan predator, fungsi lain mangrove bagi tuntong laut adalah sebagai pengatur mortalitas dalam penyesuaian air yang bersalinitas tinggi. Sehingga tuntong laut mampu bertahan di sungai dan muara yang salinitasnya rendah. Oleh karena itu, kerusakan mangrove dapat mempengaruhi perubahan struktur, komposisi dan fungsi bagi tuntong laut. Peranan masyarakat dalam menjaga ekosistem mangrove sangat menentukan pola pemanfaatan lahan. Aktivitas pemanfaatan lahan perlu mempertimbangkan upaya pengelolaan secara kolektif. Upaya yang dilakukan berupa tindakan restorasi, rehabilitasi dan reklamasi. Peningkatan terhadap layanan ekosistem dievaluasi dengan penilaian terhadap indikator-indikator yang terlibat, metode kuantifikasi dan strategi pengelolaan. Sehingga dari hasil penilaian tersebut dapat memberikan sutu kebijakan dan pemahaman kepada masyarakat terhadap pengelolaan sumber daya mangrove.
\end{abstract}




\section{Pendahuluan}

Meningkatnya aktivitas masyarakat pesisir akan berdampak pada degradasi ekosistem mangrove, kondisi seperti ini sering kita dapatkan pada masyarakat yang mata pencaharian adalah nelayan. Sumber pendapatan dari hasil nelayan tidak memenuhi untuk kebutuhan hidup, sehingga ketergantungan masyarakat pada hutan mangrove sangat tinggi. Hal ini bisa dilihat di daerah pesisir yang ada hutan mangrove dan pemukiman masayarakat yang kondisi perekonomian terbatas, sehingga eksploitasi hutan mangrove untuk dijadikan sebagai kayu bakar atau arang, pembukaan lahan pertanian dan perikanan tidak bisa teratasi dan tidak memperhatikan aspek kelestarian lingkungan sehingga menyebabkan biodiversitas hilang akibat aktivitas-aktivitas masyarakat pesisir meningkat (Brown \& Williams, 2016).

Mangrove merupakan ekosistem utama wilayah pesisir yang mempunyai nilai penting dalam pengembangan sumber daya alam dan pembangunan berkelanjutan. Disamping itu, hutan mangrove merupakan tipe tumbuhan yang tumbuh disepanjang pantai atau muara sungai yang dipengaruhi oleh pasang surut air laut. Fungsi ekosistem akan mampu menyediakan jasa layanan ekosistem tergantung pada tingkat biodiversitas yang tersedia (Cardinale, 2011). Untuk menghindari hilangnya spesies akuatik diperlukan strategi konservasi dalam perlindungan biodiversitas perairan (Fagundes, et al. 2018). Tentunya biodiversitas dan penyediaan jasa layanan ekosistem terkait erat dalam meningkatkan kekayaan spesies (Bullock, et al. 2011). Oleh karena itu, biodiversitas yang dimiliki Indonesia memiliki potensi sebagai sumber plasma nutfah, yang wajib kelola dengan baik agar tetap terjaga kelestarian untuk generasi yang akan datang.

Suatu populasi hilang akibat dari eksploitasi sumberdaya alam berlebihan. Dalam kaitannya bertambahnya aktivitas manusia berdampak pada degradasi ekosistem mangrove wilayah pesisir sehingga menyebabkan jaring makanan dan kualitas lingkungan sehat menurun. Akibat dari aktivitas-aktivitas manusia terjadi perubahan lingkungan dan pencemaran lingkungan sehingga menyebabkan faktor kesehatan kura-kura air tawar terganggu (da Silva, et al. 2016) dan keberhasilan dalam reproduksi rendah (Outerbridge, et al. 2016). 
Aceh Tamiang memiliki ekosistem hutan mangrove alami yang mampu menghasilkan produktivitas serasah primer hutan mangrove berkisar antara 5,7 sampai 25,7 ton.ha ${ }^{-1} \cdot$ tahun $^{-1}$ dan tergolong tinggi jika dibandingkan dengan produktivitas serasah hutan daratan (Syahputra \& Aswita, 2012). Saat ini, kondisi mangrove pesisir Aceh Tamiang belum terkelola dan dimanfaatkan dengan baik sehingga menyebabkan terjadinya ancaman bagi kehidupan ekosistem perairan. Peranan mangrove secara ekologis sebagai tempat dalam mencari makanan, tempat pemijahan dan sebagai tempat berlindung dari hewan-hewan predator.

Rusaknya ekosistem mangrove sebagai habitat spesies perairan termasuk populasi tuntong laut, diperlukan upaya dalam menjamin kelangsungan habitat serta interaksi antar jenis spesies dalam memainkan peran sebagai rantai keseimbangan ekosistem. Jika kondisi habitat alami terganggu akan menyebabkan menurunnya populasi tuntong laut. Faktor biotik dan abiotik dapat mempengaruhi terjadinya perubahan ekosistem yang tentunya mempunyai kontribusi yang berbeda terhadap peranan ekosistem mangrove. Fenomena yang terjadi akibat dari kerusakan ekosistem mangrove berkurangnya peran ekologis bagi habitat bagi berbagai biota perairan terutama tuntong laut (Batagur borneoensis).

Peranan ekosistem mangrove perlu dievaluasi dari aktivitas masyarakat sekitar dalam pemanfaatan lahan. Evaluasi yang dilakukan adalah assesment (penilaian) terhadap beberapa indikator diantaranya adalah faktor abiotik dan biotik. Faktor abiotik seperti kualitas fisiko kimia air, iklim dan jasa layanan ekosistem, sedangkan faktor biotik adalah kualitas vegetasi mangrove dan kualitas vegetasi habitat riparian. Penentuan faktor biotik dan abiotik yang berkontribusi terhadap peran ekosistem mangrove diperlukan sebuah pemodelan ekologi. Sehingga bisa dilihat faktor-faktor apa saja yang berpengaruh lansung maupun tidak lansung.

Pemodelan ekologi dapat menggambarkan suatu hubungan timbal balik melalui analisis data secara kompleks dan multivariabel (Xi, 2013). Oleh sebab itu, pemodelan ekologi dapat melakukan simulasi terhadap ekosistem mangrove dalam jangka panjang dan skala luas. Sehingga bentuk penilaian dan pengukuran yang dilakukan secara kuantitatif dapat membandingkan hasil yang didapatkan. Hasil dari penilaian ini menjadi penting karena dapat memberikan informasi 
tentang peranan ekosistem mangrove dalam pengelolaan kearah yang lebih baik. Dengan demikian, pemodelan ini dapat menentukan indikator-indikator yang memiliki pengaruh perubahan ekosistem mangrove. Berdasarkan informasi yang diperoleh dari pemodelan tersebut dapat digunakan sebagai pijakan dalam menyusun rekomendasi untuk pengelolaan ekosistem mangrove sebagai habitat tuntong laut.

\section{Perilaku Tuntong Laut di Ekosistem Mangrove}

Tuntong laut (Batagur borneoensis, Schlegel \& Muller, 1844) adalah salah satu spesies kura-kura terrapin (semi aquatik) Indonesia dari ordo testudines yang statusnya dalam apendiks II termasuk critically endangered (kritis) (IUCN, 2008). Secara histori, tuntong laut tersebar di wilayah sundaland. Di Indonesia spesies ini tersebar di pesisir timur Pulau Sumatera dan Pulau Kalimantan. Saat ini berdasarkan jumlah telur yang ditemukan, populasi tuntong laut di Sumatera ditemukan di wilayah pesisir Aceh Tamiang dan berasosiasi dengan mangrove. Tuntong laut dalam beberapa bahasa daerah dikenal dengan nama belaku, tuntong semangka, dan tuntong (Sumatera), kura-kura jidat merah (Kalimantan Barat) dan tumtum (Kalimantan Timur). Sedangkan dalam bahasa Inggris dikenal sebagai painted batagur, painted terrapin, saw-jawed terrapin atau three-striped batagur.

Tuntong laut memiliki kemampuan hidup di air yang cukup lama berkisar $90 \%$, sedangkan $10 \%$ digunakan untuk berjemur diatas batang-batang atau ranting-ranting pohon yang tumbang ke sungai. Dunson \& Moll, (1980) menyatakan wilayah mangrove digunakan sebagai daerah untuk mencari makanan dan melakukan proses kawin. Tuntong laut tidak mempunyai kelenjar yang mengeluarkan air garam, sehingga ketika berada di air yang bersalinitas tinggi hanya mampu bertahan hidup paling lama dua minggu. Ketika kembali dari air yang bersalinitas tinggi ke air yang bersalinitas rendah maka dengan cepat mengganti air yang hilang dengan cara meminum air yang bersalinitas rendah dengan banyak, tetapi proses pergantian air tidak cepat seperti yang dilakukan oleh Batagur baska (Davenport \& Wong, 1986). Hal ini pernah dilakukan penelitian pada Diamondback terrapin menunjukkan perilaku penyesuaian dalam tingkat salinitas air dengan lingkungan, tetapi perubahan lingkungan yang tidak sesuai dengan perilaku hidup akan menyebabkan kematian yang tinggi (Harden, et 
al. 2015). Dengan kata lain tuntong laut mempunyai tingkat mortalitas yang tinggi ketika berada di air asin, sedangkan fungsi mangrove bagi tuntong laut adalah untuk menetralisir air garam yang masuk ke dalam tubuh tuntong laut.

Proses penangkapan dilakukan terlebih dahulu dibuatkan perangkap. Perangkap jaring-jaring yang digunakan untuk menangkap tuntong laut (Gambar 1) adalah mempunyai ukuran lubang mulut dengan ukuran 6,5-12 cm (Mali, et al. 2014). Banyak jenis dan desain perangkap untuk kura-kura. Ukuran perangkap yang akan digunakan bisa dimodifikasi sesuai dengan kondisi daerah penangkapan (Bury, et al. 2012). Saat ini upaya-upaya yang telah dilakukan oleh masyarakat dalam menyelamatkan spesies ini adalah dengan melakukan penetasan secara ex situ. Kegiatan penangkaran ini dilakukan untk menghindari terjadinya pengambilan telur oleh masyarakat atau dimakan oleh hewan predator.
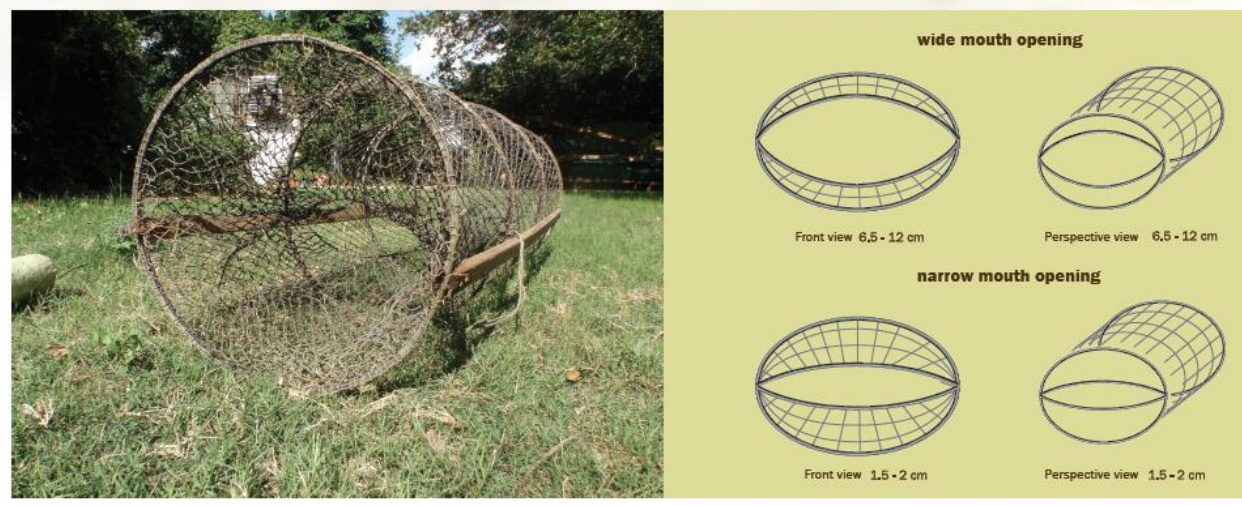

narrow mouth opening

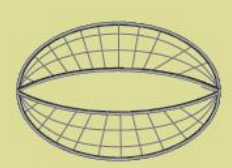

Front view $1.5 \cdot 2 \mathrm{~cm}$

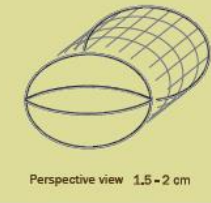

Gambar 1. Perangkap jaring yang digunakan untuk menangkap kura-kura air tawar (Mali, et al. 2014)

\section{Jasa Layanan Ekosistem Mangrove}

Ekosistem mangrove merupakan ekosistem utama yang mendukung kehidupan wilayah pesisir, karena memiliki produktivitas dan kompleksitas dari lingkungan yang khas. Diantara fungsi ekosistem mangrove adalah sebagai penyedia makanan bagi spesies perairan terutama tuntong laut. Ekosistem mangrove sebagai tempat penyangga bagi biota lain dalam mempertahankan konektivitas dengan ekosistem lainnya (Cuenca, et al., 2015). Sehingga keberadaan jenis satwa, sangat erat kaitannya dengan jenis vegetasi yang didiami (Rahardjo, 2017). Kerusakan ekosistem mangrove menyebabkan hal-hal yang dapat merugikan kehidupan manusia. Tidak hanya bagi lingkungan, tetapi juga 
menyebabkan hilangnya peluang ekonomi, hilangnya fungsi perlindungan pemukiman, bangunan dan lahan pertanian dari angin kencang atau intrusi air laut (Syahputra \& Aswita, 2012).

Jasa layanan ekosistem mangrove bagi masyarakat pesisir dan berbagai jenis hewan pesisir dapat terlindungi dari berbagai kerusakan yang diakibatkan oleh erosi dan gelombang laut. Mangrove yang membentuk tegakan sebagai spesies dasar yang mengendalikan populasi dan dinamika ekosistem, termasuk aliran energi, nutrisi, hidrologi, jaring makanan dan keanekaragaman hayati. Ditinjau dari faktor ekologi, mangrove sebagai pendukung layanan ekosistem dalam melindungi banjir, pengolahan bahan gizi dan organik serta pengontrol sedimentasi (Polidoro, et al., 2010). Sedangkan organisme yang ada di dalam suatu ekosistem dapat dibagi berdasarkan tingkatan makanan, aliran energi dan hubungan proses interaksi antar individu (Joshi \& Ghose, 2014). Hubungan antar komponen organisme dalam suatu ekosistem sebagai rantai makanan yang dapat memberikan keseimbangan atau suksesi suatu organisme yang akan berpengaruh terhadap ekosistem.

Kemampuan ekosistem dalam meregulasi merupakan layanan yang disediakan saat kondisi ekosistem stabil. Jasa layanan ekosistem saling mempengaruhi terhadap pemangku kepentingan dalam memahami landasan integritas ekologi untuk membuat konsep pengelolaan ekosistem yang komplek (Turkelboom, et al. 2015), sehingga dapat memberikan manfaat bagi pemangku kepentingan walaupun manfaat yang diterima tidak sesuai dengan yang diinginkan (Felipe-lucia, et al, 2015). Hutan mangrove merupakan suatu ekosistem tumbuhan yang tumbuh disepanjang zona integral mulai dari pantai, muara dan sungai di daerah tropik dan subtropik yang kaya akan keanekaragaman hayati (Kabir, et al. 2014 dan Cuenca, et al. 2015). Lebih lanjut (Kabir, et al. 2014) mengatakan bahwa layanan ekosistem mangrove dapat meningkatkan kualitas air dan dapat mengasimilasi pencemaran dari bahan organik, menstabilkan dan memperbaiki tanah serta menahan erosi terjangan ombak laut.

Masuknya zat pencemar akibat aktivitas masyarakat dalam bentuk pertanian dan perilaku masyarakat yang tidak konservatif dapat menyebabkan pencemaran nutrisi (nitrat dan ortofosfat) dan kualitas air lebih buruk. Sehingga ketersediaan 
agen pengendali pencemar sangat dibutuhkan di aliran sungai seperti faktor biotik dan abiotik yang berpengaruh terhadap kondisi ekosistem air mengalir (Holomuzki, et al. 2010). Arus air sebagai faktor abiotik bergantung pada debit air, ketinggian dan kemiringan sungai.

Kerusakan hutan mangrove akan mempunyai dampak yang sangat luas termasuk mempengaruhi struktur, komposisi dan fungsi (Azevedo-Ramos, et al. 2002). Tentunya kehilangan suatu populasi bisa diakibatkan adanya aktivitas antropogenik dan pemangsaan oleh predator (Steen, et al. 2012). Deforestasi yang berlebihan mengakibatkan degradasi vegetasi, ketidakseimbangan nutrisi, banjir dan perpindahan hewan dari satu area ke area lain (Meyfroidt, et al. 2013). Selain itu, perubahan struktur komunitas dalam suatu ekosistem disebabkan karena terjadinya perubahan iklim akibat pengaruh aktivitas antropogenik, seperti masuknya bahan pencemaran organik diakibatkan pembuangan limbah rumah tangga dan industri (Outerbridge, et al. 2016) dan bahkan akan berdampak pada faktor kesehatan bagi spesies yang mendiami daerah tersebut (da Silva, et al. 2016). Hal ini pernah dilakukan penelitian pada Diamondback terrapin (Malaclemyus terrapin) pada status kesehatan lingkungan yang terkontaminasi bahan organik bahwa diamondback terrapin (Malaclemyus terrapin) terkontaminasi oleh logam dan hidrokarbon (Outerbridge, et al. 2016).

\section{Peran Masyarakat Pesisir dalam Pengelolaan Ekosistem Mangrove}

Upaya konservasi yang efektif dan berkesinambungan perlu melibatkan peran aktif masyarakat. Aktivitas masyarakat dalam pemanfaatan lahan sangat berpengaruh terhadap lingkungan ekosistem. Aktivitas pemanfaatan lahan oleh masyarakat perlu mempertimbangkan aspek keberlanjutan. Sustainabilitas lingkungan menjadi faktor penting dalam memberikan jasa layanan ekosistem yang berkelanjutan. Pengelolaan berbasis lingkungan merupakan sarana yang tepat dalam mengelola biodiversitas dengan memperhatikan keseimbangan populasi berbagai jenis mahkluk hidup dan produktivitas lingkungan agar pemanfaatan lingkungan berjalan dengan baik. Beragam solusi pengelolaan dapat diaplikasikan sebagai upaya mengurangi kerusakan alam akibat pemanfaatan lahan. Maka konservasi Mangrove berbasis masyarakat sebagai pertimbangan 
dalam pengelolaan, pemantauan dan evaluasi mangrove (Cudiamat \& Rodriguez, 2017).

Keterlibatan masyarakat dalam pengelolaan ekosistem secara aktif dapat menjalankan kebijakan-kebijakan yang telah ditetapkan secara bersama oleh pengembang, pengelola dan pemerintah daerah (Cudiamat \& Rodriguez, 2017), sebagai komponen integral dari manajemen berbasis ekosistem (Yáñez-Arancibia, et al. 2013). Dalam pengelolaan keberlanjutan tergantung pada keterlibatan aktif pemangku kepentingan untuk mengembangkan dan mengimplementasikan pengelolaan sumber daya hutan (Feka, 2015). Berbagai aspek modal sosial masyarakat harus mampu diarahkan agar terjadinya proses penyelesaian masalah diantaranya kepercayaan, norma, identitas sebagai pengambil kebijakan secara kolektif agar menuju pengelolaan kolaboratif (Prayitno \& Syaifurrizal, 2017).

Diantara upaya-upaya yang bisa dilakukan diantaranya adalah upaya langsung dan upaya tidak lansung. Upaya lansung seperti restorasi, rehabilitasi dan reklamasi, dan upaya tidak langsung berupa edukasi. Unsur budaya dapat juga diterapkan dalam upaya pengelolaan yang menitikberatkan pada unsur religi dan spiritual dalam menunjang pengolaan alam yang lebih baik. Organisme target utama adalah jenis hewan yang memiliki beberapa tahapan kehidupan yang rentan hidup terhadap tekanan. Meskipun populasi tuntong laut yang menjadi perhatian konservasi dapat dipertimbangkan dalam pengembangan pemodelan distribusi spesies (Itoh, et al. 2018). Peningkatan terhadap layanan ekosistem diukur dengan penilaian, indikator, metode kuantifikasi dan strategi pengelolaan dengan pendekatan berbagai konsep (Burkhard, et al. 2014; Jamison, et al. 2016). Peran masyarakat dalam menentukan rehabilitasi, dapat dianggap sebagai keterlibatan masyarakat dalam pengelolaan sumber daya mangrove yang lebih baik (Mukherjee, et al. 2014). 


\section{DAFTAR PUSTAKA}

Azevedo-Ramos, C., De Carvalho Jr., O., \& Nasi, R. (2002). Animal Indicators, A Tool To Assess Biotic Integrity After Logging Tropical Forests. Report: Center for International Forestry Research, (February), 38 pp. https://doi.org/10.1086/511799

Brown, E. D., \& Williams, B. K. (2016). Ecological Integrity Assessment As a Metric Of Biodiversity: Are We Measuring What We Say We Are? Biodiversity and Conservation, 25(6), 1011-1035. https://doi.org/10.1007/s10531-016-1111-0

Bullock, J. M., Aronson, J., Newton, A. C., Pywell, R. F., \& Rey-Benayas, J. M. (2011). Restoration of ecosystem services and biodiversity: Conflicts and opportunities. Trends in Ecology and Evolution, 26(10), 541-549. https://doi.org/10.1016/j.tree.2011.06.011

Burkhard, B., Kandziora, M., Hou, Y., \& Muller, F. (2014). Ecosystem Service Potentials , Flows and Demands Quantification - Concepts For Spatial Localisation, Indication And Quantification. Journal of The International Association For Landscape Ecology, 32(December 2013), 1-32. https://doi.org/10.3097/LO.201434

Bury, R. B., Ashton, D. T., Germano, D. J., Karraker, N. E., Reese, D. A., \& Schlick, K. E. (2012). Sampling of Turtles: Trapping and Snorkeling. Northwest Fauna, 7, 37-50.

Cardinale, B. J. (2011). Biodiversity Improves Water Quality Through Niche Partitioning. Nature, 472(7341), 86-91. https://doi.org/10.1038/nature09904

Cudiamat, M. A., \& Rodriguez, R. A. (2017). Abundance, Structure, and Diversity of Mangroves in a Community-Managed Forest in Calatagan, Batangas, Verde Island Passage, Philippines. Asia Pacific Journal of Multidisciplinary Research, 5(3), 27-33.

Cuenca, G., Abreo, N. A. S., \& Ranara, C. T. B. (2015). Mangrove Ecosystems and Associated Fauna with Special Reference to Mangrove Crabs in the Philippines: A Review. Journal Metrics, (July). https://doi.org/10.7718/ijec.v15i1.998

da Silva, C. C., Klein, R. D., Barcarolli, I. F., \& Bianchini, A. (2016). Metal contamination as a possible etiology of fibropapillomatosis in juvenile female green sea turtles Chelonia mydas from the southern Atlantic Ocean. Aquatic Toxicology, 170, 42-51. https://doi.org/10.1016/j.aquatox.2015.11.007

Davenport, J., \& Wong, T. M. (1986). Observations on the water economy of the estuarine turtles Batagur baska (gray) and Callagur borneoensis (Schlegel and Muller). Comparative Biochemistry and Physiology -- Part A: Physiology, 84(4), 703-707. https://doi.org/10.1016/0300-9629(86)90391-9

Dunson, W. A., \& Moll, E. O. (1980). Osmoregulation in Sea Water of Hatchling Emydid Turtles, Callagur borneoensis, from a Malaysian Sea Beach. 
Journal of Herpetology, 14(1), 31-36.

Fagundes, C. K., Vogt, R. C., de Souza, R. A., \& De Marco Jr, P. (2018). Vulnerability Of Turtles To Deforestation In The Brazilian Amazon: Indicating Priority Areas For Conservation. Biological Conservation, 226(August 2017), 300-310. https://doi.org/10.1016/j.biocon.2018.08.009

Feka, Z. N. (2015). Sustainable Management Of Mangrove Forests In West Africa: A New Policy Perspective? Ocean and Coastal Management, 116, 341-352. https://doi.org/10.1016/j.ocecoaman.2015.08.006

Felipe-lucia, M. R., Martín-lópez, B., Lavorel, S., Berraquero-díaz, L., EscaleraReyes, J., \& Comin, F. A. (2015). Ecosystem Services Flows: Why Stakeholders , Power Relationships Matter. PLoS ONE, 1-21. https://doi.org/10.1371/journal.pone.0132232

Harden, L. A., Midway, S. R., \& Williard, A. S. (2015). The Blood Biochemistry Of Overwintering Diamondback Terrapins (Malaclemys terrapin). Journal of Experimental Marine Biology and Ecology, 466, 34-41. https://doi.org/10.1016/j.jembe.2015.01.017

Holomuzki, J. R., Feminella, J. W., \& Power, M. E. (2010). Biotic Interactions In Freshwater Benthic Habitats. Journal of the North American Benthological Society, 29(1), 220-244. https://doi.org/10.1899/08-044.1

Itoh, S., Takeshige, A., Kasai, A., \& Kimura, S. (2018). Modeling The Coastal Ecosystem Complex: Present Situation And Challenges. Fisheries Science, 84(2), 293-307. https://doi.org/10.1007/s12562-018-1181-x

IUCN. (2008). Batagur borneoensis , Painted Terrapin Assessment by: Asian Turtle Trade Working Group.

Jamison, S.-L., Robertson, M., Engelbrecht, I., \& Hawkes, P. (2016). An Assessment Of Rehabilitation Success In An African Grassland Using Ants As Bioindicators. Koedoe - African Protected Area Conservation and Science, 58(1), 16 pages. https://doi.org/10.4102/koedoe.v58i1.1383

Joshi, H. G., \& Ghose, M. (2014). Community Structure, Species Diversity, And Aboveground Biomass Of The Sundarbans Mangrove Swamps. Tropical Ecology, 55(3), 283-303.

Kabir, M., Abolfathi, M., Hajimoradloo, A., Zahedi, S., Kathiresan, K., \& Goli, S. (2014). Effect Of Mangroves On Distribution, Diversity And Abundance Of Molluscs In Mangrove Ecosystem : A Review. AACL Bioflux, 7(4), 286-300.

Mali, I., Brown, D. J., Ferrato, J. R., \& Forstner, M. R. J. (2014). Sampling Freshwater Turtle Populations Using Hoop Nets: Testing Potential Biases. Wildlife Society Bulletin, 38(3), 580-585. https://doi.org/10.1002/wsb.427

Meyfroidt, P., Lambin, E. F., Erb, K. H., \& Hertel, T. W. (2013). Globalization Of Land Use: Distant Drivers Of Land Change and Geographic Displacement Of Land Use. Current Opinion in Environmental Sustainability, 5(5), 438444. https://doi.org/10.1016/j.cosust.2013.04.003

Mukherjee, N., Sutherland, W. J., Dicks, L., Hugé, J., Koedam, N., \& DahdouhGuebas, F. (2014). Ecosystem Service Valuations Of Mangrove Ecosystems 
To Inform Decision Making And Future Valuation Exercises. PLoS ONE, 9(9), 1-9. https://doi.org/10.1371/journal.pone.0107706

Outerbridge, M. E., O'Riordan, R., Fort, D. J., \& Davenport, J. (2016). Ecotoxicological Assessment of Diamondback Terrapin (Malaclemys terrapin) Pond habitat, Prey and Eggs in Bermuda. Marine Pollution Bulletin, 102(1), 36-43. https://doi.org/10.1016/j.marpolbul.2015.12.006

Polidoro, B. A., Carpenter, K. E., Collins, L., Duke, N. C., Ellison, A. M., Ellison, J. C., ... Yong, J. W. H. (2010). The Loss Of Species: Mangrove Extinction Risk And Geographic Areas Of Global Concern. PLoS ONE, 5(4). https://doi.org/10.1371/journal.pone.0010095

Prayitno., G., \& Syaifurrizal, M. (2017). Social Capital and Public Participation on Planning in Coastal Area Development. IOP Conference Series: Earth and Environmental Science PAPER, 79(1).

Rahardjo, P. (2017). Ecosystem Approach Studying Development of North Coast Jakarta. IOP Conference Series: Earth and Environmental Science, 79(1). https://doi.org/10.1088/1755-1315/79/1/012009

Steen, D. A., Gibbs, J. P., Buhlmann, K. A., Carr, J. L., Compton, B. W., Congdon, J. D., ... Wilson, D. S. (2012). Terrestrial Habitat Requirements of Nesting Freshwater Turtles. Biological Conservation, 150(1), 121-128. https://doi.org/10.1016/j.biocon.2012.03.012

Syahputra, O. H., \& Aswita. (2012). Integrated Coastal Management In Pusong Cium Island For Habitat Of Tuntong Laut (Batagur Borneoensis). Laporan Hasil Penelitian.

Turkelboom, F., Thoonen, M., Jacobs, S., Garcia-liorente, M., Martin-Lopez, B., \& Berry, P. (2015). Ecosystem Service Trade-offs and Synergies. OpenNES, (27), 1-6.

Xi, W. (2013). Ecological Modeling for Informing Forest Restoration and Management. Forest Research: Open Access, 03(01), 105-106. https://doi.org/10.4172/2168-9776.1000e105

Yáñez-Arancibia, A., Day, J. W., \& Reyes, E. (2013). Understanding the Coastal Ecosystem-Based Management Approach in the Gulf of Mexico. Journal of Coastal Research, 63(April), 244-262. https://doi.org/10.2112/SI63-018.1 